\title{
Isolamento de Alcaligenes faecalis em peixe Betta splendens Regan, 1910 no Brasil
}

\author{
Isolation of Alcaligenes faecalis in fish Betta splendens Regan, 1910 in Brazil \\ Roberio Gomes Olinda ${ }^{1 *}$, Francisco Marlon Carneiro Feijón ${ }^{2}$, Jael Soares Batista ${ }^{1}, J^{\prime}$ sé Ticiano \\ Arruda Ximenes de Lima $^{3}$
}

RESUMO: Descreve-se um caso de infecção por Alcaligenes faecalis em peixe ornamental Betta splendens, incluindo avaliação clínica, patológica e bacteriológica. Um peixe fêmea, com peso de $16 \mathrm{~g}$, inicialmente demonstrou discreta lesão escoriativa no tegumento, inapetência, emagrecimento progressivo, letargia, dispneia e aumento de volume na região lateral esquerda. Constataram-se em necropsia a presença de exoftalmia bilateral, opacidade de córnea, ascite e abscesso no subcutâneo provocando distensão da cavidade celomática. As alterações histológicas da pele se caracterizaram por abscesso, necrose, hemorragia e infiltrado inflamatório constituído principalmente de heterófilos. No exame microbiológico com exsudato e sangue venoso isolou-se exclusivamente $A$. faecalis.

PALAVRAS-CHAVE: Alcaligenes faecalis; infecção bacteriana; peixe ornamental; patologia.

\begin{abstract}
This paper aimed to describe one case of infection by Alcaligenes faecalis in an ornamental fish Betta splendens, including clinical, pathological, and bacteriological evaluation. A female fish weighing $16 \mathrm{~g}$ initially showed discrete ulcerative lesions in the integument, inappetence, progressive weight loss, lethargy, dyspnea, and increased volume in the left lateral region. Necropsy revealed bilateral exophthalmia, corneal opacity, ascites, and subcutaneous abscess causing distension of the celomatic cavity. Histological changes of the skin were characterized by abscess, necrosis, hemorrhage, and inflammatory infiltrate consisting mainly of heterophils. Microbiological assays using the exudates and venous blood isolated exclusively $A$. faecalis.
\end{abstract}

KEYWORDS: Alcaligenes faecalis; bacterial infection; ornamental fish; pathology. 
Infecçóes bacterianas em peixes ornamentais são influenciadas por fatores de estresse que podem ser provenientes de má qualidade da água, alta densidade de estocagem, transporte, lesóes traumáticas e alimentação inadequada (Musa et al., 2008), que normalmente desencadeiam supressão imunológica, fundamental na patogênese de doenças bacterianas em peixes. As bacterioses estão associadas à morbidade e mortalidade em peixes ornamentais, causadas por diferentes bactérias, especialmente as gram-negativas, que têm sido isoladas como agentes patogênicos em peixes infectados naturalmente em ambientes aquáticos (RoBerTs et al., 2009).

Alcaligenes faecalis são bastonetes gram-negativos curtos, de aproximadamente $1 \mu \mathrm{m}$ de diâmetro por 2 a $3 \mu \mathrm{m}$ de comprimento, dimórficos, móveis, flagelados, aeróbicos e pertencentes à família Achromobacter (SACHDEVA; BARDHAN, 1963). Essa bactéria é um micro-organismo saprófito, constituinte da microbiota fisiológica entérica de animais domésticos e humanos (KAHVECI $e t$ al., 2011), considerada como emergente para enfermidades transmitidas através de alimentos (SiLva JúNIOR, 2005). Este trabalho tem o objetivo de relatar os aspectos clínico, bacteriológico e histológico da infecção por $A$. faecalis em um peixe Betta splendens.

$\mathrm{O}$ animal com 6 anos de idade, fêmea, pesando $16 \mathrm{~g}$, alimentado com ração comercial peletizada, era criado em um aquário doméstico. No histórico clínico, o proprietário relatou que o peixe ornamental, em intervalo de 30 dias aproximadamente, apresentou uma pequena lesão ulcerativa no tegumento, hiporexia, emagrecimento progressivo, letargia, dispneia e ataxia. Adicionalmente, o animal demonstrou despigmentação, perdas de escamas do epitélio e aumento de volume na região lateral esquerda.

Durante a necropsia constataram-se exoftalmia bilateral, opacidade de córnea, ascite e um abscesso. O abscesso tinha dimensão de $1,5 \mathrm{~cm}$ de diâmetro, revestido por uma membrana cística, amarelada, saliente e irregular, de consistência líquida, que provocava distensão da cavidade celomática. Havia, ainda, edema, hemorragia e congestos dos órgãos cavitários, necrose e exsudato com flocos brancos amarelados de fibrina, caracterizando uma peritonite fibrinosa difusa (Fig. 1A).

Fragmentos de tecidos foram fixados em formol tamponado a $10 \%$, incluídos em parafina, seccionados à espessura de $4 \mu \mathrm{m}$ e corados com hematoxilina e eosina (HE). Para análises microbiológicas foram colhidas amostras assépticas do sangue via punçáo venosa, exsudato contido no abscesso subcutâneo e amostra da ração. Foram semeadas em ágar sangue de carneiro desfibrinado (5\%) e ágar MacConkey, em estufa bacteriológica de atmosfera aeróbica, e temperatura de $37^{\circ} \mathrm{C}$ por 24 a 48h. A identificação foi baseada nas características macroscópicas, morfotintorial pela coloração do método de gram e a definição do perfil bioquímico (MACFADDIN, 2000).

Histologicamente observou-se abscesso delimitado por cápsula fibrosa, preenchido com infiltrado inflamatório misto, constituído principalmente por heterófilos íntegros e degenerados, macrófagos, escassos linfócitos e agregados de bactérias, além de necrose e detritos celulares em meio à fibrina. $\mathrm{Na}$ derme e na musculatura esquelética foram evidenciadas áreas de hemorragia, com hemosiderina, e infiltrado inflamatório misto nas áreas que circunscrevem a lesão abscedativa (Fig. 1B).

No exame bacteriológico observou-se o crescimento de colônias com os seguintes aspectos morfológico: pequenas, convexas, amareladas, textura lisa e bordas irregulares. Essas características são relatadas nessa espécie conforme KonEMAN et al. (2001). Quando submetidas à coloração de gram foram observados bacilos negativos. Para identificação da espécie, os testes bioquímicos realizados foram catalase $(+)$, citocromo oxidase $(+)$, oxidação de glicose $(-)$, motilidade $(+)$, citrato $(+)$, redução de nitrato (-), teste em ágar DNase (-), indol (-) Triple-Sugar-Iron (TSI) (-) e urease (-) (MacFaddin, 2000).

Clinicamente, o estado séptico desse peixe foi determinado pela observação dos sinais clínicos, sugestivos de bacterioses em peixes, associados ao isolamento bacteriológico no sangue. Esses sinais são frequentemente relatados em casos de septicemia em peixes, provocadas por outros agentes bacterianos (Lima et al., 2008).
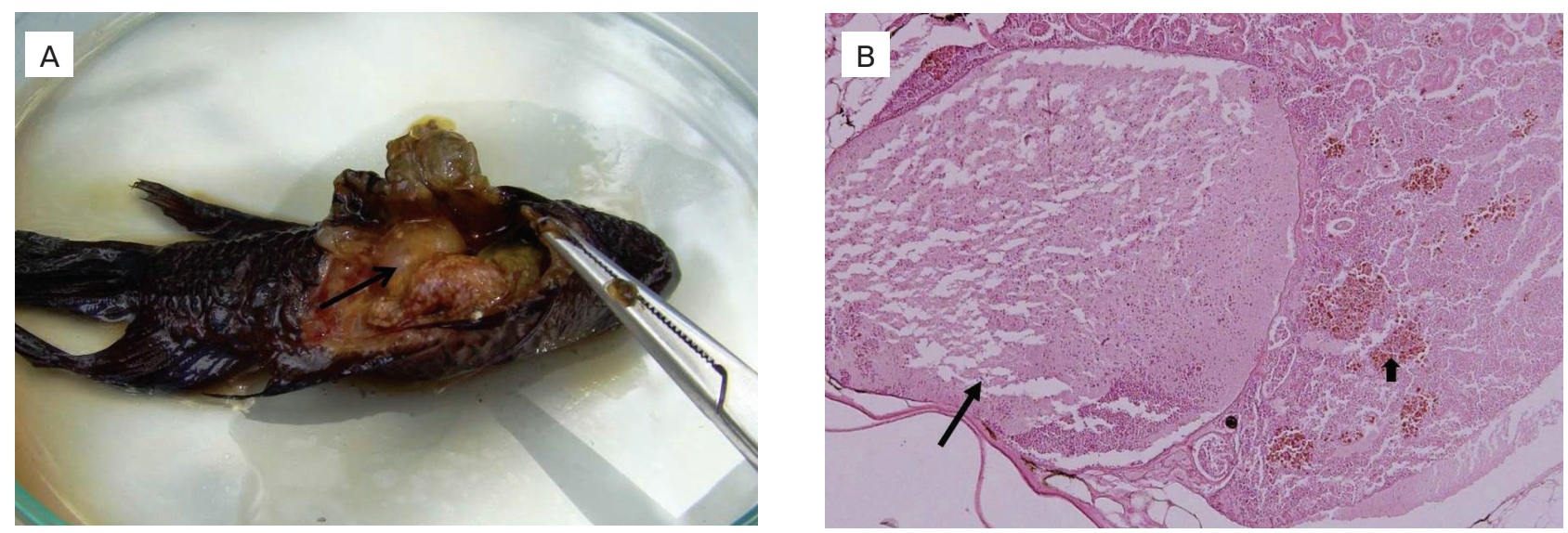

Figura 1. Abscesso subcutâneo em peixe Betta splendens, infiltrando na cavidade celomática. (A) Nota-se presença de tecido necrosado, edemaciado e exsudato fibrinoso difuso na cavidade celomática (seta). (B) Nota-se cavidade preenchida por heterófilos e detritos celulares em meio à deposição de fibrina, revestido por cápsula de tecido conjuntivo (seta), além de hemorragias no tecido muscular (cabeça de seta). HE, obj. $10 x$, barra $=240 \mu \mathrm{m}$. 
A hipótese aventada para a causa morte desse peixe é que ocorreu provavelmente inapetência, septicemia e compressão dos órgãos da cavidade celomática pelo abscesso. Estudos raramente têm documentado a importância clínica do potencial patogênico de $A$. faecalis em causar sepse em humanos e em animais domésticos (KaHVeci et al., 2011), geralmente relatam como agente etiológico oportunista decorrente de situaçóes estressantes que resultam em supressão imunológica.

Neste caso clínico, a ração foi descartada como fonte de infecção do peixe, portanto, é sugestivo que a provável via de contaminação tenha sido a água do aquário. Pesquisas microbiológicas em águas de estabelecimentos comerciais especializados isolaram e tipificaram $A$. faecalis em 45 a $65 \%$ das amostras dos aquários analisadas (TRUST; BARTLETT, 1974).

As bacterioses podem envolver mais de um micro-organismo, ocorrendo algumas vezes de forma simultânea, no entanto, neste caso foi verificada uma infecção monomicrobiana. Todavia, a virulência e o papel patogênico da $A$. faecalis ainda náo foram elucidados, necessitando de mais estudos direcionados aos aspectos de sanidade aquícola. Segundo BelÉm-Costa; Cyrino (2006), a maioria dos agentes etiológicos causadores de processos mórbidos em peixes ainda não foram identificados e nem estudado.
As lesôes histológicas observadas foram: abscesso, infiltrado inflamatório e lesóes necróticas marcantes no tecido subcutâneo, se prolongando no tecido muscular. Esses achados estáo em consonância com as lesôes teciduais promovidas por outras bactérias septicemiantes em peixes, capazes de induzir lesóes de natureza inflamatória, caracterizadas por injúrias sistêmicas (Lima et al., 2008). As doenças infecciosas são observadas com maior frequência em peixes ornamentais do que em peixes selvagens, pois provavelmente na natureza a debilidade ocasionada pela condição mórbida facilita a predaçáo sumária e o peixe é eliminado do sistema, dificultando o seu registro (Thatcher, 1981).

As bactérias da família Enterobacteriaceae já foram destacadas como importantes agentes patogênicos no ecossistema aquático, sendo sua presença detectada por meio de exames da pele, brânquias e intestinos de peixes, podendo estar envolvidas como agente etiológico primário, desencadeando epizootias na piscicultura, quando há um desequilíbrio no sistema bactéria-hospedeiro-ambiente (HuBER et al., 2004). Neste caso sugere-se que a bactéria $A$. faecalis seja considerada agente patogênico para organismos aquáticos e que a sua presença em aquário seja acompanhada de modo experimental para confirmação de resultados e compreensão dos mecanismos etiopatogênicos.

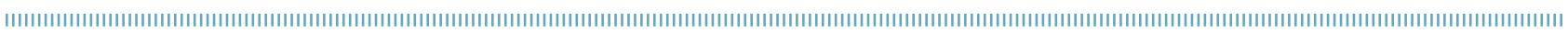

\section{REFERÊNCIAS}

BELÉM-COSTA, A.; CYRINO, J.E.P. Antibiotic resistence of Aeromonas hydrophila isolated from Piaractus mesopotamicus (Holmberg, 1887) and Oreochromis niloticus (Linnaeus, 1758). Scientia Agricola, v.63, n.3, p.281-284, 2006.

HUBER, I.; SPANGGAARD, B.; APPEL, K.F.; ROSSEN, L.; NIELSEN, T.; GRAM, L. Phylogenetic analysis and in situ identification of the intestinal microbial community of rainbow trout (Oncorhynchus mykiss, Walbaum). Journal of Applied Microbiology, v.96, n.1, p. $117-132,2004$.

KAHVECI, A.; ASICIOGLU, E.; TIGEN, E.; ARI, E.; ARIKAN, H.; ODABASI, Z.; OZENER, C. Unusual causes of peritonitis in a peritoneal dialysis patient: Alcaligenes faecalis and Pantoea agglomerans. Annals of Clinical Microbiology and Antimicrobials, v.10, n.12, p.1-3, 2011.

KONEMAN, E.W.; ALLEN, S.D.; JANDA, W.M.; SCHRECKENBERGER, P.C.; WINN JR, W.C. Diagnóstico Microbiológico. Texto e Atlas Colorido. $5^{\mathrm{a}}$ ed. Rio de Janeiro: MEDSI, 2001. 1465p.

LIMA, L.C.; FERNANDES, A.A.; COSTA, A.A.P.; VELASCO, F.O.; LEITE, R.C.; HACKETT, J.L. Isolation and characterizaton of Edwardsiella tarda from pacu Myleus micans. Arquivo Brasileiro de Medicina Veterinária e Zootecnia, v.60, n.1, p.275-277, 2008.
MACFADDIN, J.F. Biochemical tests for identification of medical bacterial. $3^{\text {a }}$ ed. Philadelphia: Lippincott Williams \& Wilkins, 2000. $901 \mathrm{p}$.

MUSA, N.; WEI, L.S.; SHAHAROM, F.; WEE, W. Surveillance of bacteria species in diseased freshwater ornamental fish from aquarium shop. World Applied Sciences Journal, v.3, n.6, p.903-905, 2008.

ROBERTS, H.E.; PALMEIRO, B.; WEBER, E.S. Bacterial and parasitic diseases of pet fish. Veterinary Clinics of North America: Exotic Animal Practice, v. 12, n.3, p.609-638, 2009.

SACHDEVA, L.D.; BARDHAN, P.N. Bacteriological study of an Alcaligenes faecalis strain: a food poisoning epidemic. Indian Journal of Pathology and Microbiology, v.37, p. 128-133, 1963.

SILVA JÚNIOR, E.A. Manual de controle higiênico sanitário em alimentos. São Paulo: Livraria Varela, 2005. p.245-285.

THATCHER, V.E. Patologia de peixes da Amazônia Brasileira, 1. Aspectos gerais. Revista Acta Amazonica, v.1 1, n.1 p.125-140, 1981.

TRUST, T.J.; BARTLETT, K.H. Occurrence of potential pathogens in water containing ornamental fishes. Applied Microbiology, v.28, n.1, p.35-40, 1974. 